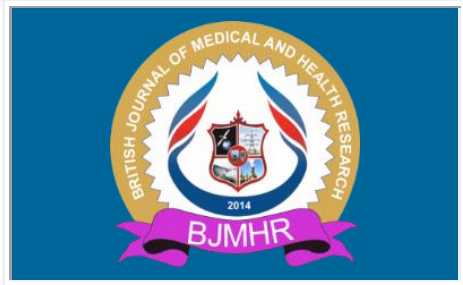

\title{
BJMHR
}

British Journal of Medical and Health Research

Journal home page: www.bjmhr.com

\section{Validation Of Uterine Artery Doppler In Predicting Intra- Uterine Growth Restriction Among Pregnant Women With Pre- Existing Hypertension}

\author{
Misbah Hanif*, Syeda Batool Mazhar \\ 1.Obstetrics \& Gynaecology, Department Of Obstetrics And Gynaecology, Mch Center, \\ Federal Government polyclinic Hospital, Islamabad \\ 2.Professor \& Head Department of Obstetrics \& Gynaecology, MCH Center, Unit I, PIMS, \\ Islamabad
}

\section{ABSTRACT}

Hypertensive disorders complicate $12 \%$ to $22 \%$ of all pregnancies. Intrauterine growth restriction is one of the fetal outcomes in mothers with hypertension. Doppler studies are done to predict pregnancy outcome in patients with hypertension. We planned this study to determine the role of uterine artery Doppler at 22 to 26 weeks of gestation for predicting IUGR in women with pre-existing hypertension. A cross sectional validation study was undertaken in the Department of Obstetrics \& Gynaecology, MCH Center, Unit I, PIMS, Islamabad from June 2014 to June 2015. Both primigravida and multigravida women with pre-existing hypertension were enrolled. Pregnancies with congenital abnormalities, complications like diabetes, cardiac disease and autoimmune disease were excluded. Women without satisfactory attainment of sonography due to technical reasons, lost to follow-up and cases who were not delivered in MCH Center, PIMS, were also excluded. There were 15 (26.7\%) cases of IUGR in normal RI Doppler group and 20 (35.7\%) abnormal RI Doppler group. The average birth weight was slightly higher in normal RI group $2.9+1.1 \mathrm{~kg}$ compared to $2.3+0.7 \mathrm{~kg}$ in abnormal RI group. RI on Doppler ultrasound had sensitivity and specificity of $57.1 \%$ and $53.2 \%$ in predicting IUGR whereas the PPV and NPV were found to be $35.7 \%$ and $73.2 \%$ respectively. RI on Doppler ultrasound is a reasonably good predictor of IUGR. Though it was reasonably sensitive the value of PPV was not that high (35.7\%).

Keywords; Pregnancy, pre-existing hypertension, uterine artery Doppler, IUGR

Please cite this article as: Hanif M et al., Validation Of Uterine Artery Doppler In Predicting IntraUterine Growth Restriction Among Pregnant Women With Pre-Existing Hypertension. British Journal of Medical and Health Research 2020. 


\section{INTRODUCTION}

Hypertensive disorder during pregnancy affects both mother and fetus. It complicates approximately $12 \%$ to $22 \%$ of all pregnancies ${ }^{1}$. Hypertension contributes to intrauterine growth restriction (IUGR) in which the fetus fails to achieve the genetically predetermined growth potential and may be caused by maternal, fetal, placental, or other external factors. IUGR is considered when estimated fetal weight by sonogram falls below the $10^{\text {th }}$ percentile gestational age. IUGR is not only associated with increased in perinatal morbidity and mortality but also long term health outcomes ${ }^{2}$.

IUGR is clinically suspected when ultrasound estimates of fetal size or weight are abnormal and Doppler studies of maternal and fetal circulation helps to differentiate growth retarded fetuses secondary to placental dysfunction from those due to aneuploidy, genetic syndrome and intrauterine infections. A better understanding of fetal hemodynamic changes occurring in IUGR will likely lead to target monitoring in such fetuses leading to appropriate timing of delivery only when fetal risks exceed neonatal risks ${ }^{2}$.

The incidence of IUGR varies from region to region and even in the same region it varies in different subpopulations. In Pakistan, the incidence of IUGR is estimated at around $25 \%{ }^{3}$. The incidence of pathological IUGR is estimated to be $4 \%$ to $8 \%$ in developed countries and $6 \%$ to $30 \%$ in developing countries. Fetuses with IUGR have a two-fold to six-fold increase in perinatal morbidity and mortality ${ }^{4}$.

Pre-eclampsia and IUGR are major contributors to perinatal mortality and morbidity. Both are characterized by impair trophoblastic invasion of the maternal spiral arteries. The ideal screening test would accurately predict the development of adverse pregnancy outcomes early enough to provide a window for preventive interventions ${ }^{5}$. Early identification of IUGR enables attractions of various measures which improves the outcome and reduce perinatal mortality ${ }^{6}$.

In hypertensive disorder of pregnancy, in addition to per abdominal examination and blood pressure monitoring of IUGR is possible with additional diagnostic tools like Ultrasonography. The ultrasound assists in the clinical estimation of fetal size, fetal weight ${ }^{7}$ and combined with Doppler of uterine artery and can pick pathological growth restriction due to fetal placental dysfunction ${ }^{8}$. Use of umbilical artery, middle cerebral artery and uterine artery Doppler has been the mainstay of assessment ${ }^{9}$. To see that whether Doppler screening using high RI cutoff is more sensitive we aimed to determine the positive predictive value by using the resistance index of uterine artery to predict the onset of IUGR in hypertensive pregnancy between 22 and 26 weeks of gestation. 


\section{MATERIALS AND METHOD}

\section{Study Definitions:}

\section{Intrauterine growth restriction (IUGR):}

IUGR is considered when estimated fetal weight by sonogram falls below the $10^{\text {th }}$ percentile for gestational age.

\section{Pre-Existing Hypertension/Chronic Hypertension:}

Blood pressure $>140 \mathrm{mmHg}$ systolic and/or $>90 \mathrm{~mm}$ diastolic prior to conception or in first half of pregnancy without an apparent underlying cause.

\section{Resistance Index of Uterine Artery (RI):}

It is a measure of pulsatile blood flow that reflects the resistance to blood flow caused by micro vascular bed distal to the site of measurement .The resistance index (RI) of uterine artery with gestational age appropriate cutoffs, is the most commonly used index criteria for an abnormal RI have varied from a single cutoff (e.g. RI $>0.58)$ to a percentile cutoff value (e.g. $75^{\text {th }}, 90^{\text {th }}$, $95^{\text {th }}$ ) it is measured best at 24 weeks of gestation.

\section{Study Design and Subjects:}

This was a cross sectional validation study. Conducted at the Obstetrics and Gynaecology department (in collaboration with the radiology department), MCH PIMS, Islamabad. The duration was one year from June 2014 to June 2015. The patients with singleton pregnancy up to 20 weeks of gestation of mothers with pre-existing hypertension and those both primigravida and multigravida were included. The cases with congenitally abnormal fetuses, pregnancies complicated by diabetes, cardiac diabetes and autoimmune disease were excluded. Pregnancies in which the satisfactory resistance index cannot be attained due to technical reasons and those women who did not delivery at MCH Center as well as lost to follow up cases were excluded from the study.

\section{Procedure:}

Ethical approval was taken from the hospital ethical committee. Patients who presented in OPD for booking and admitted in antenatal ward through OPD or emergency before 20 weeks gestation were screened. Informed consent was administered to all selected cases. Patient information was collected on a predesigned proforma from patient's case notes, antenatal booking cards and in case admitted patients from their file records. Doppler scan was performed in collaboration with the radiology department. Patients were followed up till delivery as per standardized protocol for women with pre-existing hypertension and the fetal weight was recorded. 
The resistance index of uterine artery was recorded between 22 and 26 weeks of gestation. The women were divided in to two groups based on whether the resistance index was normal or abnormal. The prevalence of IUGR in both of these groups was confirmed at birth.

\section{Statistical considerations:}

Sample size was calculated using WHO sample size calculator keeping level of significance at $5 \%$, study power at $80 \%$ and anticipated proportion in normal group as $10 \%$. The sample size (n) was 56 cases. The subjects were selected using consecutive sampling and 56 cases of normal and 56 cases of abnormal RI on Doppler were enrolled in this study.

Data was entered in SPSS (statistical software) version 17. The frequency and percentages of IUGR were measured. The rate of IUGR was compared among normal and abnormal RI categories. The sensitivity and specificity of RI on Doppler ultrasound in predicting IUGR was also calculated.

\section{RESULTS AND DISCUSSION}

Of the 56 cases in with normal RI, 30 (53.4\%) were nullipara and 26 (46.6\%) were multipara whereas in RI group, 29 (51.7\%) cases were nullipara and 27 (48.3\%) multipara. Moreover, 32 $(57.1 \%)$ cases were primigravida in normal RI and 30 (53.4\%) in abnormal RI group. There was no statistical difference in the gestational history between normal RI and abnormal RI groups. Doppler predicted 35 (31.2\%) cases of IUGR in this study. (Figure I)



Figure I: Prediction of IUGR on Doppler ultrasound in the study

The mean gestational age at the time of ultrasound in normal RI group was $23.5+1.7$ weeks whereas in abnormal RI group it was $24.1+1.5$ weeks. Similarly, the average RI was $0.63+$ 0.12 in normal RI and $0.74+0.08$ in abnormal RI group. In the normal RI group, $9(16.1 \%)$ cases were found to have unilateral notch and $5(8.9 \%)$ had bilateral notch. While, in the 
abnormal RI group, 8 (14.2\%) cases had unilateral notch and $16(28.5 \%)$ had bilateral notch. (Table 1)

Table 1: Maternal parameters in the study patients

\begin{tabular}{llll}
\hline & Normal RI (n=56) & $\begin{array}{l}\text { Abnormal } \\
\text { RI (n=56) }\end{array}$ & p-value \\
\hline $\begin{array}{l}\text { Gestational age } \\
\text { (weeks) at Delivery }\end{array}$ & $38.1+2.0$ & $37.8+1.8$ & 0.56 \\
$\begin{array}{l}\text { Mean + SD } \\
\text { Mode of delivery }\end{array}$ & $21(37.5 \%)$ & $31(55.1 \%)$ & 0.05 \\
$\begin{array}{l}\text { Cesarean section } \\
\text { SVD }\end{array}$ & $35(62.5 \%)$ & $25(44.9 \%)$ & \\
IUGR & $15(26.7 \%)$ & $20(35.7 \%)$ & 0.30 \\
\hline
\end{tabular}

There were 15 (26.7\%) cases with IUGR in normal RI group and 20 (35.7\%) in the abnormal RI group. In the normal RI group there were 30 (53.4\%) males and 26 (46.6\%) females whereas in abnormal RI group, there were 27 (48.3\%) baby boys and 29 (51.7\%) girls. The average birth weight was significantly higher in normal RI group $2.9+1.1 \mathrm{~kg}$ compared to $2.3+0.7 \mathrm{~kg}$ in abnormal RI group (p-value $=0.008$ ). The Apgar score was found up to 7, in $11(19.6 \%$ ) in normal RI group cases compared to $20(35.7 \%)$ in the abnormal RI group and this difference was found statistically significant $(\mathrm{p}$-value $=0.005)$. There were $3(5.3 \%)$ child deaths in normal RI group and $7(12.5 \%)$ in the abnormal RI group (p-value $=0.32)$. (Table 2 )

Table 2: Fetal outcome in the study patients

\begin{tabular}{llll}
\hline & $\begin{array}{l}\text { Normal RI } \\
(\mathbf{n = 5 6})\end{array}$ & $\begin{array}{l}\text { Abnormal RI } \\
(\mathbf{n = 5 6})\end{array}$ & p-value \\
\hline $\begin{array}{l}\text { Gender } \\
\text { Male }\end{array}$ & $30(53.4 \%)$ & $27(48.3 \%)$ & 0.50 \\
$\begin{array}{l}\text { Female } \\
\text { Birth weight }\end{array}$ & $26(46.6 \%)$ & $29(51.7 \%)$ & \\
$\begin{array}{l}\text { Mean + SD } \\
\text { Apgar score (5 min) }\end{array}$ & $2.9+1.1$ & $2.3+0.7$ & 0.008 \\
$\begin{array}{l}\text { Up to 7 } \\
\text { 8 or above }\end{array}$ & $11(19.6 \%)$ & $20(35.7 \%)$ & 0.05 \\
NICU admission & $45(80.4 \%)$ & $36(64.3 \%)$ & \\
Perinatal Death & $17(30.3 \%)$ & $23(41.1 \%)$ & 0.23 \\
\hline & $3(5.3 \%)$ & $7(12.5 \%)$ & 0.32 \\
\hline
\end{tabular}

In this study RI on Doppler ultrasound had sensitivity and specificity of $57.1 \%$ and $53.2 \%$ in predicting IUGR whereas the PPV and NPV was found to be $35.7 \%$ and $73.2 \%$ respectively. (Table 3).

Table 3: Validity of RI in predicting IUGR

\begin{tabular}{lc}
\hline Diagnostic parameters & Value (\%) \\
\hline Sensitivity & 57.1 \\
Specificity & 53.2 \\
PPV & 35.7 \\
NPV & 73.2 \\
\hline
\end{tabular}


In the current study a significant proportion of IUGR was predicted using Doppler ultrasound, there were one third of the cases with IUGR. The current study of uterine artery Doppler ultrasound found sensitivity, specificity, PPV and NPV of $57.1 \%, 53.2 \% .35 .7 \%$ and $73.2 \%$ respectively in the prediction of IUGR. Many previous studies have also found reasonable predictive strength of Doppler ultrasound. In the study by Nagar et al uterine artery Doppler had sensitivity, specificity, PPV and NPV of 25\%, 94.5\%, $28.5 \%$ and $93.5 \%$ respectively in predicting IUGR ${ }^{10}$. Moreover, in the study by Razieh DF and colleagues, uterine artery Doppler had sensitivity and specificity of $75 \%$ and $83 \%{ }^{11}$. Arduini et al while studying the high risk population obtained a sensitivity and specificity of $62.5 \%$ and $71.1 \%$ in predicting IUGR $^{12}$. Furthermore, using the persistence of bilateral notch or the high RI, Bower and colleagues reported sensitivity of $45 \%$ and specificity of $96 \%$.

Montenegro et al adopting high RI as a Doppler abnormality criterion demonstrated a high sensitivity but low PPV ${ }^{13}$. Compared to our findings, where a high RI was taken as abnormal Doppler, the variable findings of different predictive parameters show inconsistency. There is a need to compare other parameters of Doppler ultrasound and compare them with RI parameter so that after correlation a more strong and sensitive diagnostic tool could be used in these women.

The cutoff value of RI of uterine artery has been discussed widely in various A scientific papers and attempts have been made to overcome this problem by calculating average values of different vessels of the uterine circulation or using the highest RI or even the lower value of RI as the variable of interests. Many investigators have suggested the cutoff value of 0.70 of $\mathrm{RI}^{11}$. In the current study we applied cut offs value of RI of 0.75 .

In the current study cesarean section was found significantly higher in the abnormal RI group $(55.1 \%)$ compared to $(37.5 \%)$ in the normal RI group ( $\mathrm{p}$-value $=0.05)$. Comparatively in the study by Nagar et al $42 \%$ had cesarean section ${ }^{10}$.

Moreover, this study found a compromised condition of newborns with abnormal RI study as having significantly low apgar score and low birth weights. This has been witnessed by many previous investigators as well ${ }^{14,15}$. In the present study $21.1 \%$ fetuses died, majority was from abnormal RI group who had IUGR. Nagar et al also reported that 5 (13.8\%) fetuses out of 36 with IUGR died. They concluded that combination of uterine and umbilical artery Doppler is the best indicator of pre eclampsia and IUGR ${ }^{10}$.

The advantages of the study include its rarity, as this was one of the first studies from the local as well as national level health facilities on this topic. A significant number of hypertensive women have been selected to determine the pregnancy outcome.

There were some limitations of this study as well. The RI parameter of Doppler ultrasound has been evaluated alone and not in comparison with other Doppler parameters. The outcomes of 
the maternal and fetal parameters have not been assessed in further detail. Overall this study has demonstrated some relevance of uterine artery Doppler in the prediction of IUGR in women with pre-existing hypertension during pregnancy.

\section{CONCLUSION:}

Based on the results of this study it is concluded that abnormal RI on Doppler ultrasound is a reasonably good predictor of IUGR. Though it was reasonably sensitive the value of PPV was low (35.7\%). The current results demonstrate that Doppler study should be the primary imaging modality of choice for fetomaternal surveillance in patients with hypertension in pregnancy. For generalization of our results, there is a further need of large scale validity based studies to determine the strength of Doppler in the national level healthcare settings.

\section{REFERENCES:}

1. Walfisch A, Hallak M, Hypertension .In: Steer PJ, Weiner CP, Gonik B, James DK (editors). High risk pregnancy: management options. $3^{\text {rd }}$ ed. Singapore: Elsevier; 2005 : p.772.

2. Rizzo G, Arduini D. Intrauterine growth restriction: diagnosis and management - a review .minervaginecol.2009 OCT:61(5):411-20.

3. Shamim A, Khan HO, Rana KA. Intrauterine growth restriction: a perspective for Pakistan. J Pak Med Assoc. 1999 Feb ;49(2):50-2.

4. Fortner KB, Ahthaus JE, Gurewitsch ED. Gestational complication. In: Syzmanski L, Fox HE, Wallach EE, Fortner KB (editors). The Johan Hopkins Manual of Gynaecology and obstetrics. $3^{\text {rd }}$ ed .New York: Lippincott \& Wilkins; 2006, P.114.

5. Zhong Y, Tuuli M, Odibo AO, First-trimester assessment of placenta function and the prediction of preeclampsia and intrauterine growth restriction. Prenat Diagn 2010; 30(4):293-308.

6. Rytlewski K, Kusmierska K, Howezak J. Feto-placental blood flow-practical remarks. Przegl Lek . 2009; 66(7): 394-402.

7. Shepard MJ, Richards VA, Berkowitz RL. An evaluation of two equations for predicting fetal weight by ultrasound. Am J Obstet Gyncelogy 1986; 93(3):212-6.

8. Falo AP. Intrauterine growth retardation (IUGR): prenatal diagnosis by imaging. Pediatr Endocrinol Rev 2009; 6 suppl 3: S326-31.

9. Hoffman C, Glan HL. Assessing the 'at-risk' fetus: Doppler ultrasound. Curr Opin Obstet Gynecol 2009; 21(2):161-6.

10. Nagar T, Sharma D, Choudhary M, Khoiwal S, nagar RP, Pandita A. the role of uterine and umbilical arterial Doppler in high risk pregnancy: A prospective observational study from India. Clin Med Insights : Reproductive Health 2015; 9: 1-5 
11. Razieh DF, Mahdyeh M, Saedeh A, Reza NM. Uterine artery Doppler sonography in predicting preeclampsia and IUGR in 14-46 weeks gestation. World Applied Science J $2013 ; 22: 197-201$

12. Arduini D, Rizzo G, Romanini C, Mancuso S. Uteroplacental blood flow-velocity waveforms as predictors of pregnancy induced hypertension. Eur J Obstet Gynecol Reprod Biol 1987; 26:335-41

13. Montenegro CAB, Chaves E, Pessoa LG, Rezzende J, Oliveira AS. Valor preditivo para a toxemia do Doppler das arterias uterinas. Progresos en diagnostic pregnatal 1998; 10:16-19

14. Williams obstetrics $\left(24^{\text {th }} \quad\right.$ ed.). McGraw-Hill Professional. 2014. ISBN 9780071798938.

15. Lo JO, Mission JF, Caughey AB. Hypertensive disease of pregnancy and maternal mortality. Current opinion in obstetrics \& Gynaecology 2013; 25 (2): 124-32.

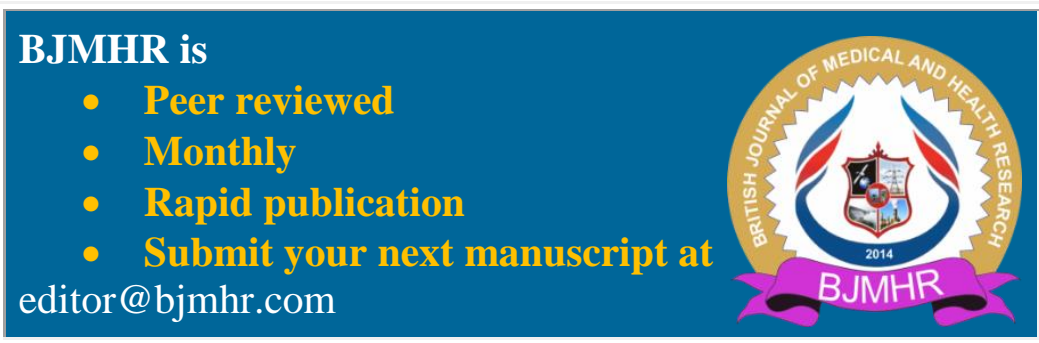

